\title{
Owls and rabbits: predation against substandard individuals of an easy prey
}

\author{
Vincenzo Penteriani, Maria Del Mar Delgado, Paola Bartolommei, Carlotta Maggio, \\ Carlos Alonso-Alvarez and Graham J. Holloway
}

V. Penteriani (correspondence) and M. D. M. Delgado, Dept. of Conservation Biology, Estación Biológica de Doñana, C.S.I.C., Avda. de María Luisa s/n., Pabellón del Perú, Apdo. 1056, 41013 Seville, Spain. E-mail: penteriani@ebd.csic.es. — P. Bartolommei, Sezione di Ecologia Comportamentale, Etologia e Gestione della Fauna, Univ. Of Siena, Dept. of Scienze Ambientali “'G. Sarfatti”, Via Mattioli 4, 53100 Siena, Italy. Carlotta Maggio. - G. J. Holloway, Centre for Wildlife Assessment and Conservation, School of Animal and Microbial Sciences, University of Reading, Whiteknights, PO Box 228, Reading RG6 6AJ, UK. - C. Alonso-Alvarez, Instituto de Investigación en Recursos Cinegéticos, IREC (CSIC, UCLM, JCCM), Ronda de Toledo, s/n, 13071 Ciudad Real, Spain.

\begin{abstract}
The interactions among the multiple factors regulating predator-prey relationships make predation a more complex process than previously thought. The degree to which substandard individuals are captured disproportionately seems to be better a function of the difficulty of prey capture than of the hunting techniques (coursing vs. ambushing predators). That is, when the capture and killing of a prey species is easy, substandard individuals will be predated in proportion to their occurrence in the prey population. In the present study, we made use of eagle owls Bubo bubo and their main prey, the rabbit Oryctolagus cuniculus: (a) the brightness of the white tails of rabbits seems to be correlated with the physical condition of individuals, (b) by using the tails of predated rabbits as an index of individual condition, we found that eagle owls seem to prefer substandard individuals (characterized by duller tails), and (c) by using information from continuous radiotracking of 14 individuals, we suggest that the difficulty of rabbit capture could be low. Although the relative benefits of preying on substandard individuals should considerably decrease when a predator is attacking an easy prey, we hypothesise that the eagle owl preference for substandard individuals could be due to the easy detection of poor individuals by a visual cue, the brightness of the rabbit tail. Several elements allow us to believe that this form of visual communication between a prey and one of its main predators could be more widespread than previously thought. In fact: (a) visual signalling plays a relevant role in intraspecific communication in eagle owls and, consequently, visual signals could also play a role in interspecific interactions, and (b) empirical studies showed that signals may inform the predator that it has been perceived, or that the prey is in a sufficiently healthy state to elude the predator.
\end{abstract}

Animal predation studies have generally assumed predators prevalently prey upon substandard individuals, i.e. disadvantaged individuals in low physical condition (Errington 1946, Curio 1976). Such an assumption fits well with classical models of optimal foraging, which predict that predators should maximize their rate of energy intake by selecting the most profitable prey (Greene 1986, Giraldeau and Caraco 2000). Moreover, the degree of prey selection has mainly been considered as a function of the hunting technique of the predator (Kruuk 1972, Schaller 1967, 1972), coursing predators (e.g. species that chase their prey over long distances, like many canids and felids) have greater opportunity to attack animals in poor conditions compared to ambush predators (e.g. stalker species that tend to rely on surprise and short pursuits, like birds of prey and owls). The latter, known as "sit-and-wait" predators, should kill a more random sample of individuals due to both the stochasticity of differential encounter rates with different prey individuals when ambushing, and short time for prey selection during chases.

Recent studies have, however, demonstrated that the interactions among the multiple factors regulating predatorprey relationships (e.g. prey's group size, sex and age of the prey, prey's vigilance level, habitat type and cover, predator's tactics) make predation a more complex process than previously thought. For example, the proposed dichotomy in prey vulnerability (i.e. coursing vs. sit-andwait predators), as well as the general notion that predators prey on disadvantaged individual disproportionately from the prey population, doesn't appear to represent a general rule (e.g. Reich 1981, FitzGibbon and Fanshawe 1989, Koivunen et al. 1996, Rohner and Krebs 1996, Husseman et al. 2003). Indeed, the degree to which substandard individuals are captured disproportionately seems a function of the difficulty of prey capture (Temple 1987). That is, when the capture and killing of a prey species is easy, 
substandard individuals will be predated in proportion to their occurrence in the prey population.

Such an example, and in agreement with Husseman et al. (2003), highlights the need for additional studies (on a broad range of predator-prey systems) evaluating alternative factors that could possibly affect predation. Unfortunately, the information needed for such studies are difficult to obtain due to the fact that most predators promptly consume their prey, leaving little or no evidence to determine the condition of the captured individuals. As a consequence, most studies have been done on large mammals preying on large prey that cannot be promptly and entirely consumed (e.g. FitzGibbon and Fanshawe 1989, FitzGibbon 1990, Husseman et al. 2003), trained raptors (e.g. Kenward 1978, Temple 1987) or, more generally, on predators that made their captured preys available for analyses (e.g. regurgitated prey items; van Dobben 1952, Kniprath 1969). Although some studies used information from radiotagged prey (Keith et al. 1984, Rohner and Krebs 1996, Murray 2002), animal predation has rarely been studied by following tagged predators during hunting (e.g. Husseman et al. 2003), that is by a more direct 'predator view'. The capture and radio marking of prey was necessary to obtain information on both the conditions of preyed individuals and their vulnerability (e.g. Murray 2002), whereas predator choice was analysed by indirect evidence from the kill site or the carcass (e.g. Murray 2002, Wirsing et al. 2002). Nevertheless, if different cues from the prey could allow us to gain information on their physical condition, the continuous radiotracking of predator time budget should give us more direct and accurate information on prey vulnerability (i.e. hunting effort). Moreover, trapping and radiotagging efforts and costs would be reduced because with each tagged predator we control for a larger number of prey.

The eagle owl Bubo bubo is a sit-and-wait predator and, with the Spanish imperial eagle Aquila adalberti, the most specialized rabbit Oryctolagus cuniculus predator among European raptors (Delibes and Hiraldo 1981). This large owl reaches peak abundance in typical and cold Mediterranean regions where rabbits are widespread and abundant (Donázar 1987). Such a strong link between eagle owls and rabbits gives them an interesting predator-prey system. In fact, because predation represents a crucial factor regulating population dynamics and a strong selective force in the evolution of prey traits (Rohner and Krebs 1996, Møller and Erritzøe 2000, Johansson et al. 2004), we should expect that the greater the dependence of a predator on its prey, the more predator and prey characteristics should be mutually shaped by their interactions.

In the present work we first show that the brightness of the white tails of rabbits is correlated with the physical condition of individuals. Second, we compare the tails of the individuals predated by owls with the tails of rabbit from a shot sample (rabbits taken by hunters), revealing that the amount of substandard individuals is predominant in the eagle owl diet. Finally, by using information from radiotagged owls, we show that the capture difficulty of rabbit is low for eagle owls. Such a result supports the importance of studying animal predation from the perspective of the predator.

\section{Methods}

\section{Evaluation of rabbit conditions}

We evaluated the physical condition of rabbits by a reduced major axis (RMA) regression (Green 2001) using log of both body mass (to the nearest $10 \mathrm{~g}$, with $1 \mathrm{~kg}$ Pesola scales) and tarsus length (using a digital calliper, $90.1 \mathrm{~mm}$ ). Each rabbit was measured and weighted on the same day it was killed.

Finally, to detect if the brightness of the rabbit tail is a trait related to its body condition, we related the body conditions with the total reflectance of the tail using Pearson's correlation. Reflectance was measured as the sum of the reflectance spectra in the range 360-700 nm using a Minolta CM-2600d portable spectrophotometer (Minolta Co., Osaka, Japan) with UV (xenon flashlight source) and visible light (standard illuminant D65). To avoid biases in the brightness evaluation, the tails of both the prey and the shot samples were cleaned with a soft cloth before spectrophotometric measurements.

\section{Tails from the rabbits killed by eagle owls}

From Jan. to Sept. 2005 (i.e. from incubation to the end of the post-fledging dependence period and the beginning of juvenile dispersal) we collected 35 rabbit tails from 11 different eagle owl territories in the Sierra Norte of Seville (37830?N, 06803?W, south-western Spain; more details in Penteriani et al. 2005). The highest density of breeding territories of eagle owls ever reported for Europe (35 breeding pairs / $100 \mathrm{~km}^{2}$, Delgado and Penteriani 2007) has been recorded in this area. The high rabbit density explains this trend. Rabbit tails were collected from both the occupied nest and from food stores close to the nest. We only used recently killed rabbits (less than 24 h, i.e. the night previous to the nest visit) to avoid the possibility that long permanence on the ground or within the other prey remains in the nest could alter the brightness of the tail fur.

\section{Tails from the shot sample}

From November 2004 to March 2005 we collected 57 tails from rabbits shot by people (approx. $>50$ hunters) hunting in the game reserves within the same 11 eagle owl breeding territories in which we collected the tails of the predated rabbits.

Although in same context shot samples have been considered as biased samples (Wirsing et al. 2002), we see no reason for this in the case of the rabbits killed by owls. In fact: (a) random samples shot from a population are a standard technique that has been frequently used to assess the average condition of a wildlife population and for comparisons with preyed individuals (e.g. Kenward 1978, Temple 1987, FitzGibbon and Fanshawe 1989, Rohner and Krebs 1996), (b) the 11 nests from which we collected the rabbit tails were within the game reserve from which we gathered the shot sample, avoiding possible differences between the two samples due to habitat heterogeneity in the rabbit population (Kenward 1978), (c) rabbits were shot early in the morning and at sunset, two time periods that 
partially overlap with the owls' hunting hours (Delgado and Penteriani, unpubl. radiotracking data), avoiding a possible biased sample due to rifle shooting at night (Smith et al. 1995), and (d) because killing by shotgun and owls are both determined by the status of vigilance and ability to escape of the preyed individuals (both elements are a function of the physical condition of an individual, see Kenward 1978, FitzGibbon 1990, Murray 2002), there are no reasons why owl and shot samples should differ with respect to the health of the rabbits included in the samples. Nevertheless, and because the shot sample may tend to select weaker or juvenile individuals (Murton et al. 1974, Kenward 1978, Smith et al. 1995), when testing for owl selection an above average content of substandard individuals in the shot sample would have represented a conservative bias.

Finally, because the months over which the shot rabbits were collected (Nov.-March) partially differed from the period over which the depredated rabbits were collected (Jan.-Sept.), and predated rabbit were collected from Winter to Summer (i.e. along different periods of the reproductive cycle of rabbits), we tested for possible variation in the tail brightness between: (a) rabbits shot in the period Nov.-Dec. (i.e. two months before egg-laying, when predated rabbit are not found into the nest) and those shot in Jan.-March (i.e. the period overlapping with the collection of the tails in the owl nests); and (b) rabbits predated in the period Jan.--March and those predated from April to Sept. (i.e. when the hunting season is ended and shot samples are not available). Because there was no significant variation in the brightness of the rabbit tail in the above-cited periods (t-tests, all $\mathrm{P}>0.1$ ), sub-sets of data from shot and predated rabbits were therefore compared between them.

\section{Assessing the difficulty of prey capture}

To assess the difficulty of rabbit capture within our study area, we monitored by radiotracking the behaviour of 14 eagle owls (11 males and 3 females) breeding in the 11 nests from which we collected the tails of the predated rabbits. Radio-tagged owls were equipped with $30 \mathrm{~g}$ harness mounted backpacks (Biotrack, Wareham, Dorset, UK), with a mercury posture sensor that allowed us to discriminate hunting behaviour from other activities (see below) by changes in the radio signal of the transmitters. The weight of the tags corresponds to less than $3 \%$ of the weight of the smallest adult male $(1,550 \mathrm{~g})$ of our eagle owl population (mean9SE: 1,6679104.8 g, $\mathrm{n}=9$ males).

The capture (by simulating a territorial intrusion with a combination of a taxidermic mount of eagle owl and a net, see Penteriani et al. 2007a) and manipulation of breeding owls, was always very safe because: (a) when trapped, we immediately removed the owls from the net; and (b) they stay motionless when manipulated. After 4 years of continuous radiotracking of more than 50 eagle owls (both breeders and floaters), we never recorded a possible adverse effect of backpacks on birds or breeding performances (Delgado and Penteriani unpubl. data). The backpacks were never removed after the study due to the difficulty to trap again the same individual (Penteriani and Delgado unpubl. data).
We did continuous radiotracking from two to five times per week, from the beginning of Jan. to mid-Sept., i.e. the same period during which we collected the tails in the nests. A new owl location was recorded each time that we detected a change in the radio signals. Such changes (i.e. change of posture or position) were detected by a fixed antenna located on the roof of the car. Locations of radio-marked animals were determined using biangulation with 3-element hand-held Yagi-antenna connected to ICOM (IC-R20) portable receivers (www.icom.co.jp), beginning one hour before sunset and ending one hour after sunrise. We used ArcView v 3.2 (ESRI 1999) geographic information system (GIS) software to retrieve geographic characteristics of points representing scoter locations. Owl locations were plotted on digital 1:10,000 maps. Obviously, because females rest quite motionless in the nest during the incubation (approx. $33 \mathrm{~d}$ ) and the nestling stage (approx. 35-40 d in our study area, when all the nests are on the ground), they rhythms of activity were not accounted for from egg-laying to fledgling.

After more than 300 nights (approx. 3,000 hours) of continuous radiotracking of more than 50 owls radiotagged in the period 2003-2005 (in the context of an ongoing study), we were able to discriminate hunting behaviours from other activities (e.g. vocal displays, young feeding, roosting) when the following three conditions were contemporaneously respected. First, when the tag pulse increased its frequency and its volume changed, we assumed that the owl was shifting from a vertical and fixed position (i.e. perched individual) to a horizontal and dynamic position (i.e. flying individual). The change in volume is due to the variation of the distance between the individual and the car antenna because of the individual's movement. Second (see also Fig. 2), when the owl ceased its sunset vocal activity (during which it generally did short and rapid movements among the call perches surrounding the nest; Delgado and Penteriani 2007) and realized (a) a long flight to the hunting territory, or (b) a short flight but roosted for a long time (i.e. ambushing individual), we assumed that the owl started to hunt. Finally, when the frequency of the tag pulse increased and decreased following rhythmic successions, but the volume remained unchanged (i.e. perched individual) and the individual was not calling (because vocal displays generate similar patterns in frequency pulse), we assumed that the owl had successfully hunted and was eating the prey. Such a discrimination of hunting activity was also supported by direct observations of radiotagged individuals hunting at sunset, sunrise or full moon nights (Delgado and Penteriani, unpubl. data).

Because the main prey of owls in the study area are rabbits (approx $60 \%$ of the whole prey items; Delgado and Penteriani, unpubl. data), we can suppose that the hunting efforts that we recorded from the radiotagged individuals were mainly directed towards rabbits. To represent the foraging effort of eagle owls, we calculated the rate of prey capture, i.e. the amount of time between the beginning of a hunting session (as indicated by the above-cited second condition necessary to discriminate hunting attempts from other behaviours) and the capture of a prey. If rabbits were easy prey, tagged owls should capture their prey rapidly after they began hunting. Moreover, we computed the total amount of time spent in hunting activities during the whole 
night. If rabbits were an easy prey, tagged owls should spend the longer portion of the entire night motionless or in activities other than hunting. In fact, if owls easily caught their prey, they would not need to hunt for long periods of time as a result of repeated unsuccessful attacks or the necessity to explore several different areas per night.

\section{Results}

Residuals of the RMA, representing our index of rabbit condition, positively correlated with tail brightness $\left(\mathrm{r}_{\mathrm{p}}=\right.$ $0.29, \mathrm{P}=0.03, \mathrm{n}=55$; Fig. 1 ), confirming our hypothesis that rabbits in better body condition have brighter tails.

The comparison of tail brightness between the individuals depredated by eagle owls (2490.699209.06 nm, range $=2014.76-2824.75 \mathrm{~nm}, \mathrm{n}=35$ ), and the shot sample $(2605.869280 .66 \mathrm{~nm}$, range $=1871.69-3300.72$ $\mathrm{nm}, \mathrm{n}=172$ ) showed that preyed individuals had duller tails ( $\mathrm{t}=-2.30, \mathrm{P}=0.022)$ and, assuming the relationship between body condition and tail brightness, the preyed rabbits were in relative weak condition, i.e. the substandard individuals of the whole population.

Radiotracking of owls supported the idea that rabbits represented an easy prey in our study area. In fact, we recorded: (1) quite short time laps $(97.2962 .8 \mathrm{~min}$, ranging from 15 to $378 \mathrm{~min}$ ) between the beginning of hunting and the capture of a prey, and (2) generally low percentage of time $(16.5911 .9 \%$, ranging from 2.6 to 78.8\%; Fig. 3) spent in hunting activities compared to the length of the whole night.

\section{Discussion}

The main result of our study points at the possible dominance of substandard individuals (as revealed by their lower tail brightness compared to rabbits from the shot sample) among preyed rabbits, even when such a prey seems to be easy to capture (as showed by continuous radiotracking).

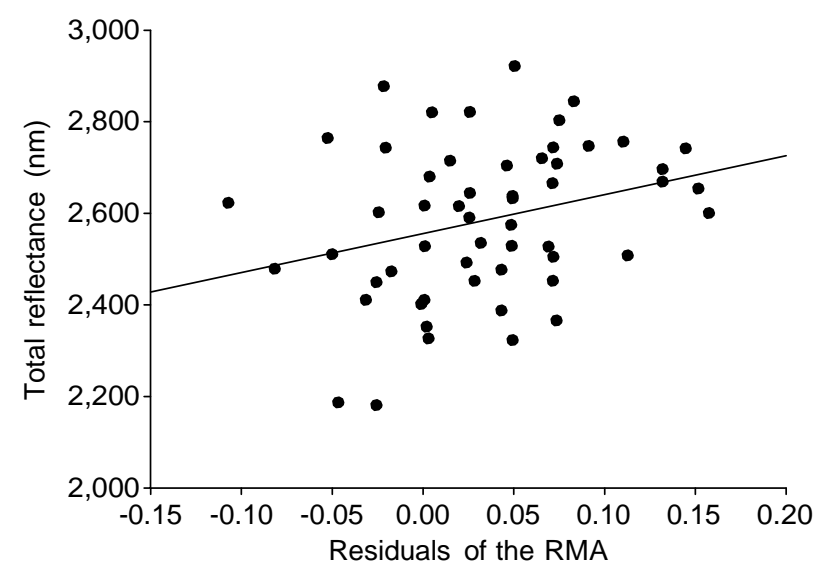

Fig. 1. The positive correlation between the residuals of the index of rabbit condition (RMA, see detail in the text) and the brightness of the rabbit tails.
A substandard individual should usually be easier to capture because it is more vulnerable to predation than a normal individual. In fact, poor body conditions may increase the rate of risk-prone behaviours (e.g. compensatory foraging) and alter predator detection or evasion abilities (Norrdahl and Korpimäki 1998, Murray 2002 and references therein, Wirsing et al. 2002). As a result, predators that prey on individuals in poor conditions have both higher probability of success and less energy expenditure. However, the relative benefits of preying on substandard individuals should considerably decrease when a predator is attacking prey that are easy to catch, i.e. when even healthy individuals can be easily captured (Temple 1987).

The ease of rabbit capture, as suggested by the hunting behaviour of tagged owls, could be also supported by the activity rhythms and habitat use of rabbits in Mediterranean Spain (Moreno et al. 1996, Penteriani et al. 2006a), where the number of diurnal and more visible predators is higher than nocturnal ones. As a consequence, the risk of predation is higher during daylight hours and rabbits (Villafuerte 1994, Moreno et al. 1996): (1) prefer to feed close to cover during the day, whereas use open habitat at night, becoming highly visible and easy to pursue prey for eagle owls, and (2) are more active at night than during the day, increasing their rate of owl encounters.

Therefore, why do eagle owls faced with an easy prey still kill substandard individuals? Theoretically, higher than expected proportions of substandard individuals in the diet of a predator may be the result of two different processes (Temple 1987). First, the predator does not make any active selection of its prey and attacks substandard and normal individuals in a proportion similar to their occurrence in the population, but its attacks are more successful with prey in poor conditions. Second, the poor conditions of substandard individuals is associated with some visual cues that the predator can perceive and learn to associate with an easy capture, even easier than the capture of a normal individual in a situation of low difficulty of capture. In this case, for a similar gross benefits but a minor cost when capturing substandard individuals, the optimal foraging theory is satisfied (Krebs 1978). Moreover, as highlighted by Greene (1986), ambush predators may more likely kill substandard individuals if some visual cues represent the main factor determining a predator attack. In our opinion, eagle owls using a sit-and-wait approach from elevated perches should result unperceived to the prey in most cases and, in a situation of low hunting difficulty, there are no reasons to suppose that the success of its attacks on substandard individuals could generate the disproportionate killing that we recorded. On the contrary, we hypothesize that owl hunting decisions could be also guided by visual cues, i.e. the brightness of the rabbit tail. This possibility does not exclude that, mainly on deep darkness, owls could localise and capture their preys by auditory cues. Obviously, in non-experimental field studies on prey choice could be difficult to separate a possible habitat quality effects from prey selection by visual signal. For example, young rabbits (a) may have duller tails than adults, (b) may not have access to the best habitats and, consequently, (c) use habitats with higher predation risk. 


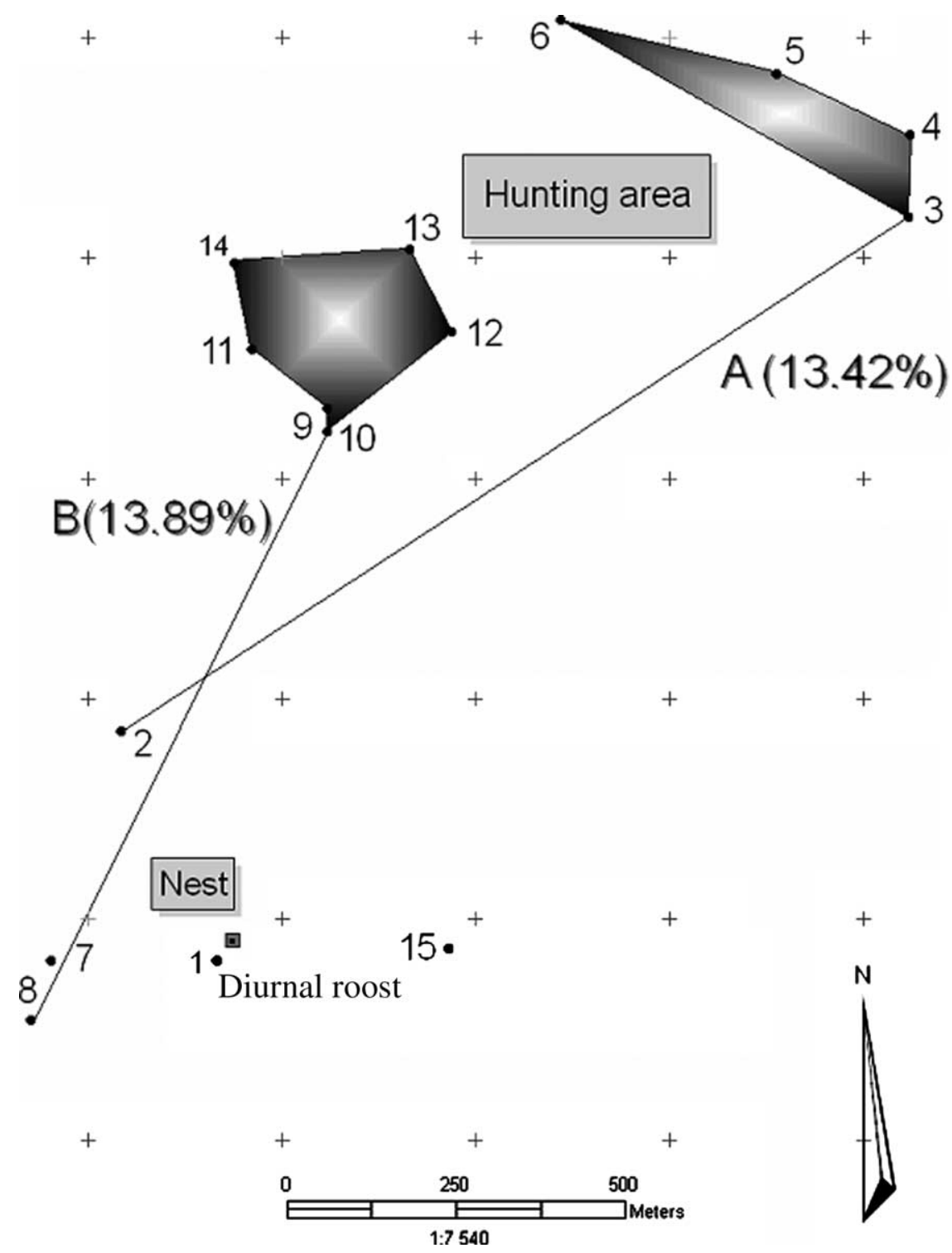

Fig. 2. A typical example of the hunting behaviour of an eagle owl (in this case a male), as recorded by an entire night of radiotracking during the nestling period (ArcMap, version 9.0). After the first flight from the diurnal roost (generally close to the nest), the first movements are within the breeding core areas, from call posts (fix 1 and 2). When sunset vocal display ceases, the eagle owl reaches its hunting territories by a longer flight (from fix 2 to fix 3). Here, it realizes some short movements until the moment in which it successfully attacks a prey (corresponding to a change in the frequency pulse, localizations 3-6). At this moment movement rates generally decrease and the owl comes back closer to the nest (fix 7). Due to the period of this example (i.e. food allocation of nestlings), the owl realized a second successful chase (from fix 8 to fix 14). Again, the beginning of hunting is characterized by a long displacement, followed by a rapid sequence of shorter movements. A and B represent the reduced percentage of time (when compared to the length of the whole night) spent by the owl during both the hunting sessions.

Several elements seem to support the hypothesis that eagle owls can use visual cues when hunting, from both the predator and the prey view. We previously showed that visual signalling plays a relevant and overlooked intraspecific role in eagle owls, both in a territorial context and parent-offspring communication (Penteriani et al. 2006b, 2007a,b). In fact, eagle owls were found to be sensitive to the brightness of both: (a) the white patch (characterized by seasonal variability and sexual dichromatism in brightness levels) on the throat of the adults, which is repeatedly exposed during vocal displays, and (b) the white edge of the mouths of fledgling eagle owls. If the brightness of white marks is important in intraspecific communication, we can suppose that this species is generally sensitive to visual communication and, therefore, visual signals could also play a role in interspecific interactions.

Although there is still little information on signals that pass between predators and prey, some evidence supports the possibility that the white mark (tail) of rabbits plays a role in predator-prey interactions. In fact, empirical studies, in both mammals and birds (Woodland et al. 1980), showed that signals may inform the predator that it has been perceived (advertising alertness; Hasson 1991 and references therein) or, as we are hypothesizing for rabbits, may inform the predator that the prey is in a sufficiently healthy state to elude the predator (advertising condition; 


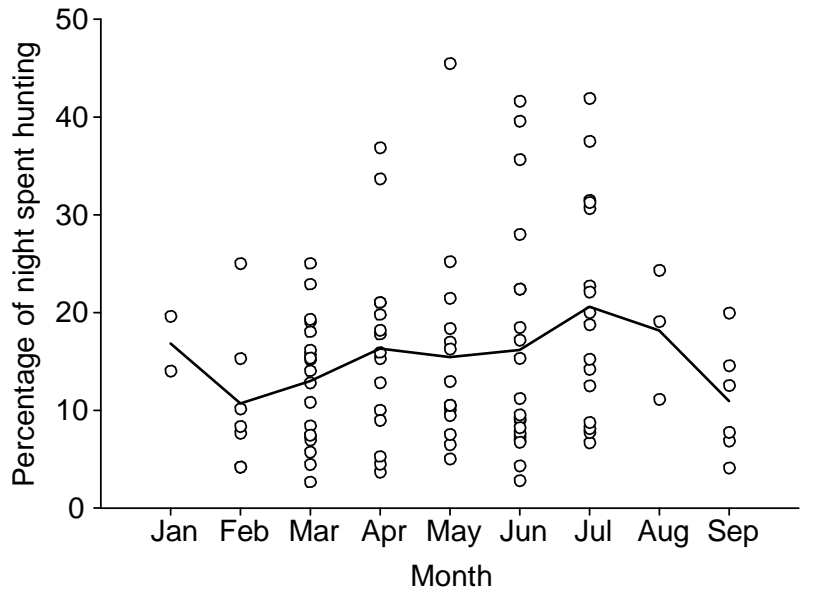

Fig. 3. The percentage of the length of the night that eagle owls spent hunting from incubation to the end of the post fledging dependence period of the young. The relatively low percentage of time spent hunting can be considered an indicator of the ease with which rabbits are predated. Each circle represents the mean hunting time of the 14 radiotagged eagle owls per night $(\mathrm{n}=$ 91). The bold line is the mean percentage of the night spent hunting.

e.g. Fitzgibbon and Fanshawe 1989). Tail-flagging in whitetailed deer Odocoileus virginianus is one of the best known examples of a visual signal directed towards ambushing predators (Caro et al. 1995 and references therein, Caro et al. 2004), although it has also been described for the fallow deer Dama dama (Alvarez et al. 1976), and Thomson's gazelle Gazella thomsoni (Caro 1986). During tail flagging the tail of the ungulate is held vertically, exposing its white underside while stotting, in a very similar way to rabbits when simply moving or running (even if rabbits do not flag voluntary, their tails and the white underside of their tail become visible every time they move). Finally, as pointed out by Caro et al. (1995), a predator is likely to interpret and respond to antipredator signals appropriately only when it has a long shared evolutionary history with its main prey, exactly as the case is with eagle owls and rabbits.

The suggested predation by visual cues is also in agreement with the hypothesis that bright coloration may signal unprofitable prey in birds (Baker and Parker 1979), which proposes that brighter individuals are signalling their higher ability to escape or avoid predators compared to duller ones. If we consider that secondary sexual traits are condition dependent (Andersson 1994), such as the brightness of the rabbit tail, we might expect that we are dealing with a mechanism that has evolved through selection by predators of substandard prey and could play also a role in rabbit sexual selection. In fact, possible differential survival of rabbits with the best secondary traits and in prime condition seems to be consistent with previous studies on the relationship between viability and features of secondary sexual characters (e.g. Petrie 1992, Møller and Nielsen 1997; but see also Rytkönen et al. 1998).

To conclude, several elements allow us to believe that this form of visual communication between a prey and one of its main predators could be more widespread than previously thought. Only experimental studies that control for the ease of the prey capture can help us to better understand this phenomenon. A variety of factors may account for the diverging results in the study on prey choice. The overlooking of predator-prey visual interactions could be one of them.

Acknowledgements - For their help with logistics we are grateful to S. Esposito, A. Gómez, G. Penteriani, the landowners who gave permission to work on their property and the C.R.E.A. of SevilleJunta de Andalucía (J. Bejarano, I. Molina, M. Pineda, N. Viqueira). The first draft was improved by the criticisms of J. W. Laundré, S. Moreno, H. Pietiäinen, R. Sandberg and two anonymous referees. Funding for this study was provided by a research project No. CGL2004-02780/BOS from the Spanish Ministry of Education and Science and LICOR43 (Diego Zamora S. A. During this work V. P. was supported by a contract from the program "Incorporación de Investigadores al Sistema Español de Ciencia y Tecnología”' (CCAA de Andalucía), M. M. D. by a doctoral grant of the Junta de Andalucía (Consejería de Educación y Ciencia) and C. A.-A. was funded by a ramón y Cajal fellowship (Ministerio de Educación y Ciencia). We trapped, manipulated and marked owls under the Junta de Andalucía - Consejería de Medio Ambiente permits No. SCFFS-AFR/GGG RS-260/02 and SCFFS-AFR/CMM RS-1904/02.

\section{References}

Alvarez, F., Braza, F. and Norzagaray, A. 1976. The use of the rump patch in the fallow deer (Dama dama). - Behaviour 3-4: 299-308.

Andersson, M. 1994. Sexual selection. - Princeton Univ. Press, Princeton.

Baker, R. R. and Parker, G. A. 1979. The evolution of bird coloration. - Phil. Trans. R. Soc. B 287: 63-130.

Caro, T. M. 1986. The functions of stotting in Thomson's gazelle: some tests of the predictions. - Anim. Behav. 34: 663-684.

Caro, T. M., Graham, C. M. and Vargas, J. K. 2004. Adaptive significance of antipredator behaviour in artiodactyls. - Anim. Behav. 67: 205-228.

Caro, T. M., Lombardo, L., Goldizen, A. W. and Kelly, M. 1995. Tail-flagging and other antipredator signals in white-tailed deer: new data and synthesis. - Behav. Ecol. 6: 442-450.

Curio, E. 1976. The ethology of predation. - Springer-Verlag, Berlin.

Delgado, M. M. and Penteriani, V. 2007. Vocal behaviour and neighbour spatial arrangement during vocal displays in eagle owl. - J. Zool. 271: 3-10.

Delibes, M. and Hiraldo, F. 1981. The rabbit as prey in the Iberian Mediterranean ecosystem. - In: Myers, K. and MacInnes, C. D. (eds). Proc. of the World Lagomorph Conference. Guelph University Press, pp. 614-622.

Donázar, J. A. 1987. Geographic variations in the diet of the eagle owls in western Mediterranean Europe. - In: Nero R. W., Clark R. J., Knapton R. J. and Hamre R. H. (eds), Biology and conservation of northern forest owl: symposium proceedings, General Technical Report RM-142, USDA, Forest Service, Fort Collins, pp. 220-224.

Errington, P. L. 1946. Predation and vertebrate populations. - Quart. Rev. Biol. 21: 221-245.

ESRI. 1999. Getting to know ArcView GIS. - Redlands: environmental systems research institute, Redlands.

FitzGibbon, C. D. 1990. Why do hunting cheetahs prefer male gazelles? - Anim. Behav. 40: 837-845.

FitzGibbon, C. D. and Fanshawe, J. H. 1989. The condition and age of Thomson's gazelles killed by cheetahs and wild dogs. - J. Zool. 218: 99-107. 
Giraldeau, L. A. and Caraco, T. 2000. Social foraging theory. - Princeton Univ. Press, Princeton.

Green, A. 2001. Mass/length residuals: measures of body condition or generators of spurious results? - Ecology 82: 14731483.

Greene, C. H. 1986. Patterns of prey selection: implications of predator foraging tactics. - Am. Nat. 128: 824-839.

Hasson, O. 1991. Pursuit deterrent signals: communication between prey and predators. - Trends Ecol. Evol. 6: 325-329.

Husseman, J. S., Murray, D. L., Power, G., Mack, C., Wenger, C. R. and Quigley, H. 2003. Assessing differential prey selection patterns between two sympatric large carnivores. Oikos 101: 591-601.

Johansson, J., Turesson, H. and Persson, A. 2004. Active selection for large guppies, Poecilia reticulata, by the pike cichlid, Crenicichla saxatilis. - Oikos 105: 595-605.

Keith, L., Cary, J. R., Rongstad, O. J. and Brittingham, M. C. 1984. Demography and ecology of a declining snowshoe hare population. - Wildl. Monogr. 90: 1-43.

Kenward, R. 1978. Hawks and doves: factors affecting success and selection in goshawk attacks on woodpigeons. - J. Anim. Ecol. 47: 449-460.

Kniprath, E. 1969. Nahrung und Nahrungserwerb des Eisvogels. - Vogelwelt 90: 81-97.

Koivunen, V., Korpimäki, E., Hakkarainen, H. and Norrdahl, K. 1996. Prey choice of Tengmalm's owls (Aegolius funereus): preference for substandard individuals? - Can. J. Zool. 74: 816-823.

Krebs, J. R. 1978. Optimal foraging: decision rules for predators. - In: Krebs, J. R. and Davies, N. B. (eds). Behavioral ecology: an evolutionary approach. Blackwell Scientific, pp. 23-63.

Kruuk, H. 1972. The spotted hyaena. - University of Chicago Press, Chicago.

Møller, A. P. and Erritzøe, J. 2000. Predation against birds with low immunocompetence. - Oecologia 122: 500-504.

Møller, A. P. and Nielsen, J. T. 1997. Differential predation cost of a secondary sexual character: sparrowhawk predation on barn swallows. - Anim. Behav. 54: 1545-1551.

Moreno, S., Villafuerte, R. and Delibes, M. 1996. Cover is safe during the day but dangerous at night: the use of vegetation by European wild rabbits. - Can. J. Zool. 74: 1656-1660.

Murray, D. L. 2002. Differential body condition and vulnerability to predation in snowshoe hares. - J. Anim. Ecol. 71: 614-625.

Murton, R. K., Westwood, N. J. and Isaacson, A. J. 1974. A study of wood-pigeon shooting: the exploitation of a natural animal population. - J. Appl. Ecol. 11: 61-81.

Norrdahl, K. and Korpimäki, E. 1998. Does mobility or sex of voles affect risk of predation by mammalian predators? - Ecology 79: 226-232.

Penteriani, V., Delgado, M. M., Alonso-Álvarez, C. and Sergio, F. 2007a. The importance of visual cues for nocturnal species: eagle owls signal by badge brightness. - Behav. Ecol. 18: 143147.

Penteriani, V., Delgado, M. M., Alonso-Álvarez, C., Viqueira, N., Sergio, F., Bartolommei, P. and Thompson, L. 2007b. The importance of visual cues for nocturnal species: eagle owl fledglings signal with white mouth feathers. - Ethology 113 : 934-943.

Penteriani, V., Delgado, M. M., Maggio, C., Aradis, A. and Sergio, F. 2005. Development of chicks and pre-dispersal behaviour of young in the Eagle Owl Bubo bubo. - Ibis 147: 155-168.

Penteriani, V., Fortuna, M. A., Melián, J. C., Otalora, F. and Ferrer, M. 2006a. Can prey behaviour induce spatially synchronic aggregation of solitary predators? - Oikos 113: 497-505.

Penteriani, V., Alonso-Álvarez, C., Delgado, M. M. and Sergio, F. 2006b. Brightness variability in the white badge of the eagle owl. - J. Avian Biol. 37: 110-116.

Petrie, M. 1992. Peacocks with low mating success are more likely to suffer predation. - Anim. Behav. 44: 585-586.

Reich, A. 1981. Sequential mobilization of marrow fat in the Impala (Aepyceros melampus) and analysis of condition of wild dog (Lycaon pictus) prey. - J. Zool. 94: 409-419.

Rohner, C. and Krebs, C. J. 1996. Owl predation on snowshoe hares: consequences of antipredator behaviour. - Oecologia 108: 303-310.

Rytkönen, S., Kuokkanen, P., Hukkanen, M. and Huhtala, K. 1998. Prey selection by sparrowhawks Accipiter nisus and characteristics of the vulnerable prey. - Ornis Fenn. 75: 7787.

Schaller, G. B. 1967. Hunting behaviour of the cheetah in the Serengeti National Park. - East Afr. Wildl. J. 6: 95-100. Schaller, G. B. 1972. The Serengeti lion. - University of Chicago Press, Chicago.

Smith, G. C., Pugh, B. and Trout, R. C. 1995. Age and sex bias in sample of wild rabbits, Oryctolagus cuniculus, from wild populations in southern England. - New Zeal. J. Zool. 22: 115-121.

Temple, S. A. 1987. Do predators always capture substandard individuals disproportionately from prey populations? - Ecology 68: 669-674.

van Dobben, W. H. 1952. The food of the cormorant in the Netherlands. - Ardea 34: 1-63.

Villafuerte, R. 1994. Riesgo de predación y estrategia defensivas del conejo, Oryctolagus cuniculus, en el Parque Nacional de Doñana. - PhD Thesis, University of Cordoba.

Wirsing, A. J., Steury, T. D. and Murray, D. L. 2002. Relationship between body condition and vulnerability to predation in red squirrels and snowshoe hares. - J. Mammal. 83: 707-715.

Woodland, D. J., Jaafar, Z. and Knight, M. 1980. The 'pursuit deterrent' function of 'alarm signals'. - Am. Nat. 116: 157177. 